\title{
UNTERSUCHUNGEN ÜBER DIE HALTBARKEIT VON EIERN
}

\author{
Merimaija Kyti und Lauri Tuomainen \\ Staatliche Kontrollanstalt für milchwirtschaftliche Produkte, Helsinki. \\ Milchwirtschaftliches Institut der Universität, Helsinki
}

Eingegangen am 15.8. 1968

Das Hühnerei wird vor äusseren Einflüssen nur durch die Häutchen, die poröse Schale und deren Kutikula geschützt. Ausserdem ist das Ei seinen physikalisch-chemischen Eigenschaften nach labil, weshalb es verständlich ist, dass seine Zusammensetzung sich unmittelbar nach dem Legen zu verändern beginnt. Wenn das Ei aus der im Inneren des Huhnes herrschenden Temperatur von $41^{\circ} \mathrm{C}$ in die kühlere Umgebung des Stalles gelangt, zieht sich das Innere des Eies zusammen, und es entsteht eine Luftblase. Die Grösse dieser Luftblase gilt als eine Qualitätseigenschaft, und man kann ihre Ausdehnung durch Regulierung der Lagerungstemperatur und -Feuchtigkeitsverhältnisse sowie durch gewisse Behandlungsmassnahmen vor der Einlagerung verlangsamen. Andere Veränderungen, die leicht und ohne Zerbrechen des Eies festgestellt werden können, sind die Verringerung des Gewichtes und des spezifischen Gewichtes, das Sichtbarwerden des Eigelbs bei Durchleuchtung, manchmal das Auftreten von Geruch und in einer späteren Phase die Bewegung des Eigelbs zur Schale hin. Weiter können Veränderungen in der Zusammensetzung des Ei-Inneren festgestellt werden. Das Eiweiss wird wässriger und sein $\mathrm{pH}$ steigt. Das Eigelb vergrössert sich, und die Vitellinhaut wird so schwach, dass sie beim Öffnen älterer Eier bricht. Diese leicht wahrzunehmenden Veränderungen werden durch verschiedene Vorgänge in der chemischen Zusammensetzung des Eies verursacht, die nur durch genaue Untersuchungen festgestellt werden können und die auch auf die Qualität der Eier einwirken.

Der Zweck dieser Untersuchung ist es gewesen, die Richtung der Veränderungen, die während der Lagerung in den finnischen Hühnereiern vor sich gehen, zu untersuchen und die Resultate mit entsprechenden ausländischen Untersuchungen zu vergleichen. Das hauptsächliche Augenmerk ist hierbei auf die Veränderungen gerichtet worden, die in der Trockensubstanz, dem Fett und dem Gehalt an freien Aminosäuren festzustellen sind. Auch ist der eventuelle Einfluss des Ölens auf die Haltbarkeit der. Eier untersucht worden. 
Die untersuchten Eier sind von der Genossenschaft Vientikunta Muna in fünf verschiedenen Betrieben in der Zeit zwischen dem 18. 10. und 27. 10. 1967 entnommen worden. Ein Teil des Materials wurde unmittelbar untersucht, um die Zusammensetzung des frischen Eies festzustellen. Die übrigen 320 Eier wurden in drei Gruppen eingeteilt, von denen die erste (Gruppe I) im Kühlschrank (bei $6^{\circ} \mathrm{C}$ ), die zweite (Gruppe II) bei Zimmertemperatur und die dritte (Gruppe III) geölt und in Zimmertemperatur aufbewahrt wurde. Bei der Ölung wurde ein Mineralöl der Marke Clearol gebraucht. Aus jeder Gruppe wurden 40 Eier nach einem und 40 Eier nach zwei Monaten untersucht. Nach drei Monaten wurden 40 Eier der bei Zimmertemperatur aufbewahrten geölten Eier und nach vier Monaten 40 Eier der im Kühlschrank aufbewahrten untersucht. Die Behandlung der Eier war die gleiche wie in der Untersuchung von Kyti, Tuomainen und Antila (1968) über die Zusammensetzung des frischen Hühnereies, nur mit dem Unterschied, dass die freien Aminosäuren und als Parallelprobe auch die freien Fettsäuren im rohen Ei untersucht wurden.

Bei dem Gehalt an Trockenmasse, Gesamtfett und Protein benutz man hier ebenfalls die gleichen Methoden wie in der oben genannten Untersuchung.

Die freien Aminosäuren wurden nach Ausfällung mit dem Aminosäurenanalysator von Technicon Instruments Ldt gemäss der A.O.A.C.-Methode (1965) untersucht.

Die freien Fettsäuren wurden nach der Methode von Kaufmann (1958) titriert. Nach Verseifung wurden die mit Natriumkarbonat gewaschenen Seifen mit Salzsäure freigemacht und mit Diazomethan verestert sowie im Chromatographen von Perkin Elmer, Modell 800, analysiert.

Die Einwirkung der Lagerungstemperatur und des Ölens der Eier auf die Gewichtsverluste und den Gehalt an Trockenmasse im Eigelb und Eiweiss

Der Gewichtsverlust beginnt unmittelbar nach dem Legen des Eies und setzt sich bei Standardverhältnissen linear fort, bis das Ei vollständig trocken ist. Hauptsächlich beruht der Gewichtsverlust auf der Verdunstung des Wassers aus dem Eiweiss (Romanoff und Romanoff 1963). KNowles (1962) führte einen Vergleich mit 30 Tage gelagerten Eiern durch. In seinen Versuchen gab es zwei Gruppen, von denen die eine bei $32^{\circ} \mathrm{F}\left(0^{\circ} \mathrm{C}\right)$ bei einer relativen Feuchtigkeit von $80 \%$ gelagert wurde. Hierbei war der Gewichtsverlust $0,6 \%$. Die andere Gruppe wurde bei $77^{\circ} \mathrm{F}\left(25^{\circ} \mathrm{C}\right)$ und $60 \%$ relativer Lufteuchtigkeit aufbewahrt, wobei der Gewichtsverlust $7 \%$ betrug. GrzimeK (1964) hat die von verschiedenen Forschern angegebenen Gewichtsverluste während der Kaltlagerung in sein Buch aufgenommen:

\begin{tabular}{|c|c|c|c|c|c|c|c|c|c|c|c|c|c|}
\hline & 1 & 2 & 3 & 4 & 5 & 6 & 7 & 8 & 9 & 10 & 11 & 12 & Monate \\
\hline Pennington & 0.5 & 1 & 1.5 & 2 & 2 & 2.5 & 3 & 3 & 3 & 4 & 4 & 5 & $\%$ \\
\hline Rasmusson & $0.5-$ & $1-$ & $1.5-$ & $2-$ & $2-$ & $2.5-$ & $3-$ & $3-$ & $3-$ & $4-$ & $4-$ & $5-$ & \\
\hline & 1 & 1.5 & 2 & 3 & 3.5 & 3.5 & 4 & 5 & 5 & 6 & 6 & 7 & $\%$ \\
\hline Jonkins & $\begin{array}{l}0.8- \\
1\end{array}$ & & & & & $\begin{array}{l}3- \\
4.5\end{array}$ & & & $\begin{array}{l}4.5- \\
6\end{array}$ & & & & $\%$ \\
\hline
\end{tabular}


Ưber die Vergrösserung der Luftblase gibt derselbe Forscher folgende Werte. Am Abend des ersten Tages $1.0-1.9 \mathrm{~mm}$, nach einer Lagerung von 12 Tagen bei $15^{\circ} \mathrm{C}$ 2.7-4.0 $\mathrm{mm}$ und nach einer Lagerung bei $9-10^{\circ} \mathrm{C} 2.6-3.6 \mathrm{~mm}$.

Ausser der Regulierung der Lagerungstemperatur und der Feuchtigkeit beeinflussen auch verschiedene Behandlungsmethoden der Schale die Gewichtsverluste und Eigenschaften der Eier. Von diesen Methoden ist die Einölung der Schale die bekannteste und meistgebrauchte. Schon seit 1807 haben die Dänen Leinsamenöl zur Behandlung der Eierschalen vor der Einlagerung gebraucht. Später hat man verschiedene Mineralöle anzuwenden begonnen, weil sie nur langsam oxydieren (BIGBEE et al. 1962). Der Einfluss des Ölens und der geeignetste Zeitpunkt ihrer Durchführung sind viel untersucht worden. Das Öl schliesst die Poren der Eierschale und verhindert die Verdunstung. Gleichzeitig hält sich das pH des Eiweisses niedrig, weil auch die Verdunstung des Kohlendioxyds gehemmt wird. Schwall et al. (1961) haben festgestellt, dass sich die geölten Eier 21 Tage oder mehr in der ersten Klasse (AA) gehalten haben, während die ungeölten Eier schon nach 3 Tagen in eine niedrigere Klasse (A) eingestuft werden mussten. Froning und Swanson (1962) haben über den Zeitpunkt des Ölens festgestellt, dass wenn die Eier zu

Tabelle 1. Die Einwirkung des Zeitpunktes für das Ölen sowie der Lagerungszeit und -temperatur auf die Haug-Einheiten, der Trübungsgrad, den prozentualen Anteil der dünnen Albuminschicht und das $\mathrm{pH}$.

\begin{tabular}{|c|c|c|c|c|c|c|c|c|c|}
\hline 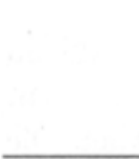 & $\begin{array}{l}\text { Zeit vor } \\
\text { Olen St }\end{array}$ & $\begin{array}{c}\text { Haug- } \\
\text { Einheiten }\end{array}$ & $\begin{array}{l}\text { Trübungs- } \\
\left.\operatorname{grad}^{*}\right)\end{array}$ & $\begin{array}{c}\text { Äussere } \\
\text { dünne } \\
\text { Schicht } \\
\%\end{array}$ & $\mathrm{pH}$ & $\begin{array}{c}\text { Haug- } \\
\text { Einheiten }\end{array}$ & $\begin{array}{l}\text { Trübungs- } \\
\left.\operatorname{grad}^{*}\right)\end{array}$ & $\begin{array}{c}\text { Äussere } \\
\text { dünne } \\
\text { Schicht } \\
\%\end{array}$ & $\mathrm{pH}$ \\
\hline & & \multicolumn{3}{|c|}{ Lagerung bei $55^{\circ} \mathrm{F}^{* *}$ ) } & \multicolumn{5}{|c|}{ Lagerung bei $32^{\circ} \mathrm{F}^{* *}$ ) } \\
\hline Anfangs- & 0 & 89 & 2.5 & 24.4 & 7.96 & 88 & 2.4 & 24.2 & 7.88 \\
\hline \multirow[t]{3}{*}{ werte } & 4 & 82 & 2.2 & 23.3 & 8.00 & 83 & 2.6 & 24.2 & 7.76 \\
\hline & 8 & 82 & 1.7 & 25.4 & 8.37 & 85 & 2.5 & 24.9 & 8.23 \\
\hline & 24 & 77 & 1.6 & 25.8 & 8.57 & 80 & 2.1 & 27.4 & 8.28 \\
\hline Lagerung & 0 & 79 & 3.4 & 29.0 & 8.12 & 80 & 3.0 & 27.8 & 7.69 \\
\hline \multirow[t]{4}{*}{15 Tage } & 4 & 78 & 2.3 & 27.3 & 7.98 & 81 & 3.1 & 29.0 & 7.70 \\
\hline & 8 & 77 & 2.1 & 31.7 & 7.96 & 77 & 2.6 & 26.3 & 7.86 \\
\hline & 24 & 73 & 1.9 & 29.9 & 8.16 & 82 & 3.1 & 29.2 & 7.91 \\
\hline & ungeölt & 72 & 1.3 & 26.9 & 9.41 & 70 & 2.0 & 29.0 & 8.79 \\
\hline Lagerung & 0 & 76 & 3.5 & 35.2 & 7.63 & 71 & 3.6 & 32.0 & 7.65 \\
\hline \multirow[t]{4}{*}{30 Tage } & 4 & 72 & 3.4 & 39.5 & 7.99 & 73 & 3.8 & 33.1 & 7.82 \\
\hline & 8 & 75 & 3.0 & 35.5 & 8.51 & 79 & 3.6 & 37.8 & 7.80 \\
\hline & 24 & 74 & 2.8 & 35.6 & 8.52 & 75 & 3.7 & 34.4 & 8.22 \\
\hline & ungeölt & 59 & 1.2 & 26.1 & 9.62 & 67 & 2.6 & 36.3 & 8.98 \\
\hline
\end{tabular}

*) Die Trübung des Eiweisses wurde mit den Punkten 1-4 bewertet, wobei 1 klarem Eiweiss und 4 sehr stark getrübtem Eiweiss entspricht.

**) Die Eier der verschiedenen Gruppen wurden auch vor dem Olen bei der angegebenen Temperatur aufbewahrt. $55^{\circ} \mathrm{F}=15^{\circ} \mathrm{C}, 32^{\circ} \mathrm{F}=0^{\circ} \mathrm{C}$. 
bald nach dem Legen eingeölt werden, dies eine anormale Verdickung der äussersten, dünnen Eiweissschicht sowie Trübung der Gallerte in der Mitte des Eiweissteils zur Folge hat. Das beste Resultat wurde in dieser Beziehung erreicht, als die Eier erst drei Tage nach dem Legen eingeölt wurden. In diesem Fall hatte das Ölen jedoch die Haltbarkeit der Eier, verglichen mit derjenigen der ungeölten Eier, nicht erhöht.

In Versuchen, die an der Kontrollanstalt für Milchprodukte in Turku durchgeführt wurden (mündliche Mitteilung), erhielt man die gleichen Resultate, wenn man die Haltbarkeit von den am ersten Tag geölten Eiern mit derjenigen von den am zweiten Tag geölten verglich. Froning und Swanson (1962) erreichten das beste Resultat mit Eiern, die 812 Stunden nach dem Legen geölt und danach bei $55^{\circ} \mathrm{F}\left(12.6^{\circ} \mathrm{C}\right)$ gelagert wurden. Wenn die Eier dagegen bei $32^{\circ} \mathrm{F}\left(0^{\circ} \mathrm{C}\right)$ gelagert wurden, konnte das Ölen unmittelbar nach dem Legen durchgeführt werden, denn die genannten Veränderungen treten bei so niedriger Temperatur auch in ungeölten Eiern auf. Die Resultate, die diese Forscher erhalten haben, sind in Tabelle 1 zu finden. Die Art des Ölens (Eintauchen in Öl oder Bespritzen der Eier damit) hat auch Einfluss auf die Ergebnisse. Die Unterschiede sind in dieser Beziehung jedoch so klein, dass sie in diesem Zusammenhang ausser acht bleiben können. Die Resultate in Tabelle 1 beziehen sich auf in Öl eingetauchte Eier. Die Tabelle zeigt die Veränderungen des $\mathrm{pH}$, die Haug-Einheiten, den prozentualen Anteil der äusseren, dünnen Eiweisschicht sowie den Trübungsgrad des Eiweisses. Der Trübungsgrad wird bestimmt, indem 1 Wertmal klares, normales Eiweiss und 4 Wertmale stark getrübtes Eiweiss bezeichnen.

Die Verdungstung aus dem Ei verursacht eine Erhöhung des Trockenmassegehalts im Eiweiss. Der prozentuale Anteil der Trockenmasse des Eigelbs verringert sich bis zu einem gewissen Punkt, wonach die Verdunstung auch hier beginnt und das Ei austrocknet. Die relative Verringerung der Trockenmasse des Eigelbs erklärt sich durch das Diffundieren der Feuchtigkeit durch die Vitellinhaut (Romanoff und Romanoff 1963). Winton und Winton (1949) haben eine Tabelle zusammengestellt, nach welcher der Wassergehalt des Eiweisses von kaltgelagerten Eiern nach 162/3 Monaten Lagerung von 86,15\% auf $84,53 \%$ gesunken und der des Eigelbs von 45,39\% auf 64,06\% gestiegen ist; bei der nächsten Kontrolle, nach 19 2/3 Monaten, ist der letztgenannte Wassergehalt schon niedriger, nämlich 50, 82 \% gewesen. Bei Zunahme des Wassergehaltes im Eiweiss und bei vergrössertem Umfang wird die Vitellinhaut geschwächt (KNowles 1962).

In der vorliegenden Untersuchung wurden die Gewichtsverluste als Prozent des ursprünglichen Gewichtes vermerkt, sie sind mit Angabe der Betriebe in den Tabellen 2 und $3 \mathrm{zu}$ finden. Nach der Statistik, die in der Untersuchung über die Zusammensetzung des frischen Eies (Kyti, Tuomainen und Antila 1968) angeführt ist, waren die durchschnittlichen Gewichte folgende: Betrieb A 50,0 g, Betrieb B 50,7 g, Betrieb C 64,6 g, Betrieb D 55,0 g und Betrieb E 49,6 g. Da das Gewicht der Eier aus dem Betrieb C bedeutend grösser war als das der anderen Eier, wurden die Resultate je Betrieb angegeben, um den eventuellen Einfluss der ursprünglichen Gewichte auf die Gewichtsverluste während der Lagerung feststellen zu können. Der Gewichtsverlust nach einer Lagerung von 4 Monaten im Kühlschrank machte bei den grossen Eiern des Betriebes C 17, 1\% aus, während er bei den übrigen Eiern 13,4-15,5 \% betrug. Nach einer Lagerung von einem Monat belief sich der Gewichtsverlust aller Eier auf 2.8-3.6 \%, nach zwei Monaten auf 6.6$9.2 \%$. Bei Zimmertemperatur betrugen die Gewichtsverluste während der Lagerung nach 
Tabelle 2. Die höchsten und die niedrigsten \%-Werte der Gewichtsabnahme sowie die Mittelwerte nach einem und zwei Monaten Lagerung.

Betrieb und

Lagerungsverhältnisse
1 Monat Lagerung

Minimum Maximum Mittel

2 Monate Lagerung

Minimum Maximum Mittel

$\begin{array}{lrrrrrrr}\text { Kühlschrank } & \text { A } & 2.9 & 4.4 & 3.3 & 5.4 & 10.0 & 6.6 \\ & \text { B } & 2.7 & 4.0 & 2.8 & 7.9 & 11.0 & 8.7 \\ & \text { C } & 3.0 & 5.3 & 3.6 & 6.0 & 12.7 & 9.2 \\ \text { Zimmertemperatur } & \text { D } & 2.5 & 3.8 & 3.3 & 3.8 & 9.3 & 6.5 \\ & \text { E } & 2.9 & 4.9 & 3.3 & 6.9 & 10.3 & 8.8 \\ & \text { A } & 4.9 & 7.2 & 6.4 & 14.0 & 20.4 & 16.3 \\ & \text { B } & 6.1 & 9.3 & 6.6 & 16.2 & 24.1 & 18.3 \\ \text { Geölt } & \text { C } & 4.3 & 7.2 & 5.6 & 6.6 & 21.1 & 17.4 \\ & \text { D } & 4.9 & 6.9 & 5.7 & 10.8 & 20.4 & 16.9 \\ & \text { E } & 5.6 & 8.7 & 6.9 & 23.8 & 31.3 & 18.8 \\ & \text { A } & 0.4 & 2.0 & 1.5 & 2.1 & 8.1 & 5.3 \\ & \text { B } & 0.9 & 4.1 & 2.8 & 6.7 & 13.4 & 9.1 \\ & \text { C } & 0.4 & 1.5 & 0.6 & 1.1 & 3.2 & 2.0 \\ & \text { D } & 0.3 & 1.2 & 0.5 & 1.1 & 6.6 & 1.9 \\ & \text { E } & 0.5 & 1.2 & 0.7 & 0.7 & 4.5 & 2.7\end{array}$

Tabelle 3. Die höchsten und die niedrigsten \%-Werte der Gewichtsabnahme sowie die Mittelwerte nach 3 und 4 Monaten Lagerung.

\begin{tabular}{cccrrrr}
\hline \multirow{2}{*}{ Betrieb } & \multicolumn{3}{c}{$\begin{array}{c}\text { Lagerung 3 Monate geölt bei } \\
\text { Zimmertemperatur }\end{array}$} & \multicolumn{3}{c}{$\begin{array}{c}\text { Lagerung 4 Monate im } \\
\text { Kühlschrank }\end{array}$} \\
\cline { 2 - 7 } & Minimum & Maximum & Mittel & Minimum & Maximum & Mittel \\
\hline & & & & & & \\
A & 5.7 & 15.3 & 8.5 & 10.0 & 16.2 & 13.4 \\
B & 6.2 & 27.7 & 18.1 & 12.9 & 17.1 & 14.9 \\
C & 0.8 & 32.6 & 2.1 & 5.1 & 22.6 & 17.1 \\
D & 2.2 & 12.5 & 6.0 & 12.0 & 17.7 & 14.3 \\
E & 1.3 & 6.6 & 3.5 & 13.4 & 17.7 & 15.5
\end{tabular}

1 Monat 5.6 - 6.9 \% und nach zwei Monaten 16.3-18.8\%. Zwischen den grossen Eiern des Betriebes $\mathrm{C}$ und den übrigen Eiern konnte kein Unterschied festgestellt werden.

In den Gewichtsverlusten zeigten sich bei den geölten Eiern bedeutende Unterschiede. Bei den Eiern der verschiedenen Betriebe betrug der Gewichtsverlust nach einer Lagerung von einem Monat 0.49-2.8\%, nach zwei Monaten 1.9-9.1\% und nach drei Monaten schon $2.1-18.1 \%$. Auch zwischen den Eiern desselben Betriebes zeigten sich besonders bei der letzten Untersuchung sehr grosse Unterschiede, der Verlust belief sich auf 0.8 - ganze $32.6 \%$. Diese Variationen beruhen wohl darauf, dass man wegen der weiten Transportstrecken nicht das Ölen aller Eier innerhalb des gleichen Zeitraumes vornehmen konnte. Auch waren wohl die Eier desselben Betriebes nicht immer genau gleich alt, selbst wenn sie am gleichen Tag gelegt worden waren. Diese Annahme wird durch Literarische Angaben über die Einwirkung des Ölungszeitpunktes aư seinen Effekt erhärtet. 
Tabelle 4. Der prozentuale Anteil der Trockenmasse in frischen und auf verschiedene Art gelagerten Eiern sowie die prozentualen Veränderungen vom Anfangswert berechnet.

\begin{tabular}{|c|c|c|c|c|c|c|c|c|c|}
\hline \multirow[t]{2}{*}{ Betrieb } & \multirow{2}{*}{$\begin{array}{c}\text { Frisches } \\
\text { Ei }\end{array}$} & \multicolumn{3}{|c|}{1 Monat gelagert } & \multicolumn{3}{|c|}{2 Monate gelagert } & \multirow{2}{*}{$\begin{array}{c}3 \mathrm{M} . \\
\text { Geölt, } \\
\text { Zimmer- } \\
\text { temp. }\end{array}$} & \multirow{2}{*}{$\begin{array}{c}4 \mathrm{M} . \\
\text { Kühl- } \\
\text { schrank }\end{array}$} \\
\hline & & $\begin{array}{l}\text { Kühl- } \\
\text { schrank }\end{array}$ & $\begin{array}{c}\text { Zimmer- } \\
\text { temp. }\end{array}$ & $\begin{array}{l}\text { Geölt- } \\
\text { Zimmer- } \\
\text { temp. }\end{array}$ & $\begin{array}{l}\text { Kühl- } \\
\text { schrank }\end{array}$ & $\begin{array}{l}\text { Zimmer- } \\
\text { temp. }\end{array}$ & $\begin{array}{l}\text { Geölt, } \\
\text { Zimmer- } \\
\text { temp. }\end{array}$ & & \\
\hline
\end{tabular}

\section{Eiweiss}

\begin{tabular}{|c|c|c|c|c|c|c|c|c|c|}
\hline A & 14.8 & 14.7 & 15.2 & 14.6 & 15.1 & 18.6 & 16.0 & 16.6 & 17.7 \\
\hline B & 13.1 & 14.1 & 14.9 & 14.0 & 14.6 & 17.6 & 16.4 & 18.2 & 17.2 \\
\hline C & 11.2 & 12.4 & 12.9 & 12.5 & 13.7 & 18.1 & 13.1 & 13.2 & 17.2 \\
\hline D & 13.4 & 12.8 & 14.0 & 13.3 & 14.3 & 17.8 & 13.6 & 14.4 & 16.4 \\
\hline E & 14.2 & 14.1 & 15.1 & 14.6 & 15.6 & 19.0 & 14.2 & 14.8 & 17.7 \\
\hline ariationen & $11.2-$ & $12.4-$ & $12.9-$ & $12.5-$ & $13.7-$ & $17.6-$ & $13.1-$ & $13.2-$ & 16.4 \\
\hline & 14.8 & 14.7 & 15.2 & 14.6 & 15.6 & 19.0 & 16.4 & 18.2 & 17.7 \\
\hline
\end{tabular}

Eigelb

\begin{tabular}{ccccccccccc} 
A & 50.8 & 49.3 & 48.3 & 48.1 & 49.6 & 47.6 & 46.8 & 46.3 & 50.3 \\
B & 51.9 & 50.1 & 49.8 & 49.0 & 51.0 & 48.7 & 47.0 & 48.4 & 50.9 \\
C & 53.3 & 51.4 & 49.7 & 50.7 & 50.9 & 49.3 & 47.9 & 48.9 & 53.2 \\
D & 53.0 & 50.2 & 49.9 & 49.4 & 50.4 & 50.2 & 47.8 & 47.2 & 50.7 \\
E & 51.6 & 50.3 & 48.8 & 48.6 & 49.9 & 50.0 & 49.6 & 46.5 & 51.0 \\
\multicolumn{2}{r}{} & & & & & & & & & \\
\multicolumn{2}{l}{ Variationen } & $50.8-$ & $49.3-$ & $48.3-$ & $48.1-$ & $49.6-$ & $47.6-$ & $46.8-$ & $46.3-$ & $50.3-$ \\
& 53.3 & 51.4 & 49.9 & 50.7 & 51.0 & 50.2 & 49.6 & 48.9 & 53.2
\end{tabular}

Veränderungen der \%-Werte Eiweiss

\begin{tabular}{|c|c|c|c|c|c|c|c|c|}
\hline \\
\hline A & -0.1 & 0.4 & -0.2 & 0.3 & 3.8 & 1.2 & 1.8 & 2.9 \\
\hline B & 1.0 & 1.8 & 0.9 & 1.5 & 4.6 & 3.3 & 5.1 & 4.1 \\
\hline C & 1.2 & 0.7 & 1.3 & 2.5 & 6.9 & 1.9 & 2.0 & 6.0 \\
\hline D & -0.6 & 0.6 & -0.1 & 0.9 & 4.4 & 0.2 & 1.0 & 3.0 \\
\hline E & -0.1 & 0.9 & 0.4 & 1.4 & 4.8 & 0.0 & 0.6 & 3.5 \\
\hline \multirow[t]{2}{*}{ Variationen } & $-0.6-$ & $0.4-$ & $-0.2-$ & $0.3-$ & $3.8-$ & $0.0-$ & $0.6-$ & $2.9-$ \\
\hline & 1.2 & 1.8 & 0.9 & 2.5 & 6.9 & 3.3 & 5.1 & 6.0 \\
\hline \multicolumn{9}{|l|}{ Eigelb } \\
\hline A & -1.5 & -2.5 & -2.7 & -1.2 & -3.2 & -4.0 & -4.5 & -0.5 \\
\hline B & -1.8 & -2.1 & -2.9 & -0.9 & -3.2 & -4.9 & -3.5 & -1.0 \\
\hline C & -1.9 & -3.6 & -2.6 & -2.4 & -4.0 & -5.4 & -4.4 & -0.1 \\
\hline D & -2.8 & -3.1 & -3.6 & -2.6 & -2.8 & -5.2 & -5.8 & -2.3 \\
\hline E & -1.3 & -2.8 & -3.0 & -1.7 & -1.6 & -2.0 & -5.1 & -0.6 \\
\hline \multirow[t]{2}{*}{ Variationen } & $-1.3-$ & $-2.1-$ & $-2.6-$ & $-0.9-$ & $-1.6-$ & $-2.0-$ & $-3.5-$ & $-0.1-$ \\
\hline & -2.8 & -3.6 & -3.6 & -2.6 & -4.0 & -5.4 & -5.8 & -2.3 \\
\hline
\end{tabular}


Bei Betrachtung der Eiergruppen als Ganzes kann jedoch festgestellt werden, dass die Gewichtsverluste der bei Zimmertemperatur gelagerten, geölten Eier bedeutend geringer waren als bei den ungeölten unter gleichen Verhältnissen gelagerten Eiern und auch deutlich geringer als bei den ungeölten, im Kühlschrank aufbewahrten Eiern. Die Veränderungen des Trockenmassegehaltes gehen aus der beigelegten Tabelle 4 hervor. Als allgemeiner Zug zeigt sich eine Zunahme des Trockenmassegehaltes im Eiweiss als Folge sowohl der Verdungstung von Wasser als auch der Diffusion des Eigelbs. Die ungeölt im Kühlschrank und geölt bei Zimmertemperatur gelagerten Eier zeigten deutlich kleinere Unterschiede als die ungeölt bei Zimmertemperatur aufbewahrten Eier. Ganz unverkennbar erweist sich dies nach zwei Monaten Lagerung, zu diesem Zeitpunkt beträgt die Zunahme der prozentualen Werte der Trockenmasse in den ungeölten Eiern im Kühlschrank 0.3 $2.5 \%$ und bei Zimmertemperatur 3.8 - 6.9\%, jedoch bei den geölten Eiern bei Zimmertemperatur $0-3.3 \%$. Noch nach einer Lagerung von drei Monaten ist die entsprechende Zunahme im Eiweiss mit Ausnahme eines Falles geringer (0.6-5.1\%) als bei zwei Monate ungeölt gelagerten Eiern (3.8-6.9\%). Die Veränderungen in den ungeölten, vier Monate im Kühlschrank aufbewahrten Eiern sind in jeder Betriebsgruppe kleiner als bei den entsprechend zwei Monate bei Zimmertemperatur gelagerten Eiern. Beim Eigelb konnten keine so grossen Unterschiede festgestellt werden. Bei den im Kühlschrank aufbewahrten Eiern sind die Veränderung des Eigelbs in dieser Beziehung am kleinsten. Nach einem Monat Lagerung hat sich der prozentuale Wert der Trockenmasse im Eigelb bei allen Gruppen um

Tabelle 5. Die prozentualen Anteile von Schale, Eiweiss und Eigelb am gesamten Gewicht der Eier aus verschiedenen Betrieben und bei verschiedenen Lagerungsverhältnissen. Die Werte sind Mittelwerte.

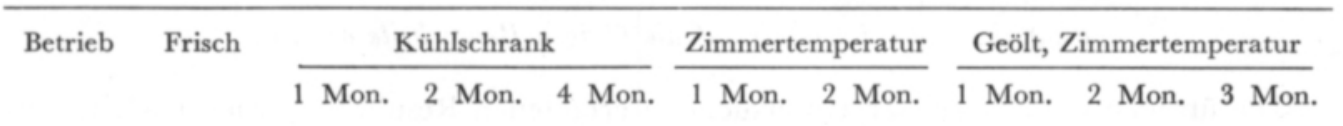

\begin{tabular}{crrrrrrrrr}
\hline Schale & & & & & & & & \\
A & 10.9 & 10.5 & 11.2 & 11.9 & 11.3 & 12.6 & 11.6 & 11.7 & 11.8 \\
B & 11.4 & 10.5 & 10.5 & 12.5 & 10.5 & 13.0 & 10.8 & 11.2 & 13.4 \\
C & 10.5 & 9.6 & 10.1 & 11.2 & 10.3 & 11.8 & 11.9 & 10.0 & 10.8 \\
D & 11.1 & 10.6 & 10.8 & 12.4 & 10.8 & 12.7 & 12.9 & 12.1 & 11.6 \\
E & 10.6 & 9.5 & 10.5 & 12.2 & 10.8 & 12.6 & 11.2 & 11.1 & 11.5 \\
& & & & & & & & & \\
Eiweiss & & & & & & & & & \\
A & 63.2 & 63.0 & 60.8 & 57.6 & 60.4 & 54.5 & 59.0 & 57.3 & 57.3 \\
B & 60.9 & 62.0 & 58.8 & 55.7 & 59.0 & 53.2 & 59.1 & 56.8 & 49.7 \\
C & 57.0 & 58.4 & 54.6 & 50.6 & 55.1 & 48.4 & 52.3 & 53.7 & 54.6 \\
D & 60.0 & 57.8 & 56.1 & 52.0 & 56.9 & 49.5 & 53.9 & 54.8 & 55.2 \\
E & 61.7 & 62.8 & 58.1 & 53.9 & 56.8 & 51.7 & 57.8 & 58.5 & 57.4 \\
& & & & & & & & & \\
Eigelb & & & & & & & & & \\
A & 24.9 & 26.0 & 27.3 & 28.5 & 27.7 & 31.7 & 28.5 & 29.2 & 29.6 \\
B & 26.8 & 27.1 & 28.2 & 30.8 & 29.8 & 35.4 & 29.3 & 30.6 & 35.6 \\
C & 31.5 & 31.7 & 34.5 & 37.0 & 33.6 & 39.2 & 34.2 & 35.2 & 33.5 \\
D & 25.8 & 31.4 & 32.3 & 34.3 & 31.0 & 36.7 & 32.2 & 32.2 & 31.9 \\
E & 27.3 & 25.8 & 29.3 & 33.2 & 32.0 & 34.5 & 30.5 & 30.9 & 31.2 \\
\hline
\end{tabular}


$1.3-3.6 \%$ und nach zwei Monaten Lagerung entsprechend um 0.9-5.4\% verringert. Die entsprechenden Werte für Eier, die drei Monate geölt bei Zimmertemperatur aufbewahrt worden sind, haben sich auf 3.5-5.8 \% und für vier Monate ungeölt im Kühlschrank gelagerte auf $0.1-2.3 \%$ belaufen.

Der Wassergehalt des Eigelbs ist durchgehend gestiegen, was auf die Diffusion aus dem Eiweiss zurückzuführen ist, wie auch aus der Literatur hervorgeht. Die Erhöhung des Wassergehalts ist um so grösser gewesen, je schlechter die Lagerungsverhältnisse gewesen sind.

Gleichzeitig mit der Abnahme des Wassergehalts im Eiweiss und der Erhöhung des Wassergehalts im Eigelb während der Lagerung verändern sich selbstverständlich auch die Gewichtsverhältnisse der Eiteile. In Tabelle 5 finden sich die relativen Anteile von Eierschale, Eiweiss und Eigelb an dem Gesamtgewicht des Eies. Die Werte sind Mittelwerte der bei jeder Beobachtung erhaltenen Prozentwerte.

Der Anteil der Schale hat sich während der Lagerung erhöht. Die ähnlichsten Resultate wurden für die Schale wie auch die übrigen Bestandteile bei Eiern gefunden, die zwei Monate bei Zimmertemperatur, drei Monate geölt bei Zimmertemperatur und vier Monate im Kühlschrank gelagert worden waren. In diesen Versuchsgruppen hat die Zunahme der prozentualen Werte der Schale 1.3-2.0\%, 0.3-2.0\% und $0.7-1.6 \%$ des Gesamtgewichts betragen, die Verringerung der Werte des Eiweisses 7.7-10.5\%, $2.4-11.2 \%$ und $5.2-8.0 \%$ sowie die Zunahme der Eigelbwerte 6.8-10.9 \%, 2.0$9.0 \%$ und $3.6-8.5 \%$. Wieder muss festgestellt werden, dass die grössten Variationen innerhalb der Gruppen bei den geölt gelagerten Eiern vorgekommen sind, was auf den Wechsel im Zeitpunkt des Ölens zurückzuführen ist.

\section{Einwirkung der Lagerung auf die übrigen Bestandteile des Eies}

Die übrigen in vorliegender Untersuchung erhaltenen Resultate werden nach Lagerungsgruppen und nicht mehr nach Betrieben angegeben. Dies beruht darauf, dass keine denklichen Unterschiede zwischen den Eiern der verschiedenen Betriebe festgestellt und die Tabellen somit klarer und leichter verständlich aufgebaut werden konnten.

\section{Die Veränderungen in den Fetten}

Ausser dem Wasser diffundiert auch in gewissem Umfang Fett durch die Vitellinhaut. In diesem Fall verläufs die Diffusion jedoch aus dem Eigelb in das Eiweiss. Hauptsächlich sind an diesem Prozess wohl die Triglyzeride beteiligt (Sмгтн 1959), und seine Voraussetzungen sind gerade die gleichen, die schnelle Feuchtigkeitsverluste fördern, also hohe Temperatur und niedrige relative Feuchtigkeit. Zu Beginn steht die Menge der diffundierenden Lipide im Verhältnis zur der Zeit, wo die Eier in ungünstigen Verhätnissen gelagert sind, aber die Reaktion verlangsamt sich nach ca. 7 Tagen. Nach einer Lagerung von drei Wochen bei $98^{\circ} \mathrm{F}$ (ca. $32^{\circ} \mathrm{C}$ ) enthielt das Eiweiss $0.275 \%$ Fett, ursprünglich hatte sein Fettgehalt $0.03 \%$ ausgemacht. Weder in den Fraktionen des Fettes noch in der Fettsäurenzusammensetzung konnten dagegen nach 6 und 12 Monaten Lagerung Veränderungen festgestellt werden (Evans et al. 1967). Auch die Zersetzung der Fette ist gering. Die 
Mengen an freien Fettsäuren betragen nach RomanofF und RomanofF (1963) bei frischen Eiern $1.72 \%$ und steigen während der drei ersten Lagerungsmonate kaum an. Nach einem Jahr kann der Gehalt an freien Fettsäuren auf $3.12 \%$ ansteigen und nach fünf Jahren auf $5.15 \%$.

In vorliegender Untersuchung konnte im prozentualen Gehalt des Eigelbs an Gesamtfett in der Trockenmasse eine kleine Senkung festgestellt werden, die bei allen Lagerungsgruppen von gleicher Grössenordnung war.

Tabelle 6. Die Fettgehalte von Eigelb und Eiweiss in $\%$ des Trockenmassegehalts.

\begin{tabular}{cccccc}
\hline Gruppen & $\begin{array}{c}\text { Frisches } \\
\text { Ei }\end{array}$ & $\begin{array}{c}1 \text { Monat } \\
\text { gelagert }\end{array}$ & $\begin{array}{c}2 \text { Monate } \\
\text { gelagert }\end{array}$ & $\begin{array}{c}3 \text { Monate } \\
\text { gelagert }\end{array}$ & $\begin{array}{c}\text { Monate } \\
\text { gelagert }\end{array}$ \\
\hline Eigelb & & & & & $57.7-61.3$ \\
I & $60.1-64.4$ & $57.2-61.6$ & $52.3-61.8$ & & \\
II & $60.1-64.4$ & $58.2-61.1$ & $57.4-62.2$ & $51.9-58.3$ & $0.5-0.7$ \\
III & $60.1-64.4$ & $56.3-62.1$ & $55.6-61.3$ & & \\
Eiweiss & & & & & \\
I & $0.2-0.5$ & $0.2-0.5$ & $0.3-0.6$ & & \\
II & $0.2-0.5$ & $0.1-0.6$ & $0.2-0.7$ & 0.7 \\
III & $0.2-0.5$ & $0.3-0.5$ & $0.3-0.6$ & & \\
\hline
\end{tabular}

Nach einer Lagerung von zwei Monaten und mehr ist der Fettgehalt in der Trockenmasse des Eiweisses ein wenig gestiegen, woraus wohl zu schliessen ist, dass das Fett aus dem Eigelb in das Eiweiss diffundiert ist, wenngleich man wegen des kleinen Materials und der verhältnismässig kurzen Lagerungszeiten keine sicheren Schlüsse ziehen kann. Die Jodzahl des Fettes im Eigelb ist nach einer Lagerungszeit von einem Monat in allen Versuchsgruppen die gleiche geblieben wie im frischen Ei. Nach zwei - vier Monaten Lagerung ist die Jodzahl leicht gesunken, wie aus Tabelle 7 ersichtlich ist, welche die mittleren Jodzahlen, nach Lagerungsgruppen geordnet, enthält.

Die Jodzahlen der aus dem Fett eluierten Fraktionen (Triglyzeride, Sterole sowie Mono- und Diglyzeride) sind alle in der gleichen Grössenordnung geblieben wie in den frischen Eiern. Zum Beispiel variierte die Jodzahl der Triglyzeride in den frischen Eiern von 72.8 - 86.5 und in allen Lagerungsgruppen von 71.1-74.0, die der Mono- und Di-

Tabelle 7. Die Jodzahl des Fettes im Eigelb.

\begin{tabular}{lccccc}
\hline & Frisch & \multicolumn{4}{c}{ L a g e r u ng } \\
\cline { 3 - 6 } & & 1 Monat & 2 Monate & 3 Monate & 4 Monate \\
& & & & & \\
Kühlschrank & 75.8 & 74.4 & 63.5 & 71.8 \\
Zimmertemperatur & 75.8 & 74.4 & 61.7 & \\
Geölt, Zimmertemperatur & 75.8 & 72.4 & 60.0 & 63.0 \\
\hline
\end{tabular}


Tabelle 8. Die Fettsäurenzusammensetzung der Triglyzeride im Eigelb von frischen und gelagerten Eiern.

\begin{tabular}{lccc}
\hline & $\begin{array}{c}\text { Frisch } \\
\%\end{array}$ & $\begin{array}{c}\text { 3 Monate geölt bei } \\
\text { Zimmertemperatur } \\
\text { gelagert } \%\end{array}$ & $\begin{array}{c}\text { 4 Monate im } \\
\text { Kühlschrank } \\
\text { gelagert } \%\end{array}$ \\
\hline $\mathrm{C}_{14}$ & 0.8 & 1.0 & 1.2 \\
$\mathrm{C}_{16}$ & 25.6 & 24.6 & 25.6 \\
$\mathrm{C}_{16} 1=$ & 2.6 & 4.2 & 5.0 \\
$\mathrm{C}_{18}$ & 5.0 & 6.0 & 5.1 \\
$\mathrm{C}_{18} 1=$ & 52.3 & 51.2 & 50.0 \\
$\mathrm{C}_{18} 2=$ & 12.8 & 12.2 & 12.2 \\
$\mathrm{C}_{20}$ & 0.9 & 0.8 & 0.9 \\
\hline
\end{tabular}

glyzeride entsprechend in frischen Eiern von 93.5-111.8 und in gelagerten von 95.798.4. Ebenso sind die Fettsäurenzusammensetzungen der Fettfraktionen die gleichen geblieben. Als Beispiel hierfür steht in Tabelle 8 die durchschnittliche Fettsäurenzusammensetzung der Triglyzeride in Eiern, die drei Monate geölt bei Zimmertemperatur und vier Monate ungeölt im Kühlschrank aufbewahrt worden sind. Als Vergleich sind die entsprechenden Werte für frische Eier angegeben.

Tabelle 9. Die Fettsäurenzusammensetzung der freien Fettsäuren.

\begin{tabular}{lccc}
\hline & $\begin{array}{c}\text { Frisch } \\
\%\end{array}$ & $\begin{array}{c}\text { 3 Monate geölt bei } \\
\text { Zimmertemperatur } \\
\text { gelagert } \%\end{array}$ & $\begin{array}{c}\text { Monate ungeölt im } \\
\text { Kühlschrank } \\
\text { gelagert } \%\end{array}$ \\
\hline $\mathrm{C}_{14}$ & 0.4 & - & 1.5 \\
$\mathrm{C}_{16}$ & 27.5 & 21.8 & 24.0 \\
$\mathrm{C}_{16} 1=$ & 2.4 & 3.1 & 5.4 \\
$\mathrm{C}_{18}$ & 7.6 & 13.2 & 12.8 \\
$\mathrm{C}_{18} 1=$ & 44.1 & 35.7 & 35.9 \\
$\mathrm{C}_{18} 2=$ & 13.4 & 17.1 & 18.4 \\
$\mathrm{C}_{20}$ & 4.6 & 9.1 & - \\
\hline
\end{tabular}

Tabelle 10. Die Gehalte an Protein im Eigelb und Eiweiss als \% der Trockenmasse angegeben.

\begin{tabular}{cccccc}
\hline Gruppen & $\begin{array}{c}\text { Frisches } \\
\text { Ei }\end{array}$ & $\begin{array}{c}\text { 1 Monat } \\
\text { gelagert }\end{array}$ & $\begin{array}{c}2 \text { Monate } \\
\text { gelagert }\end{array}$ & $\begin{array}{c}3 \text { Monate } \\
\text { gelagert }\end{array}$ & $\begin{array}{c}4 \text { Monate } \\
\text { gelagert }\end{array}$ \\
\hline $\begin{array}{c}\text { Eigelb } \\
\text { I }\end{array}$ & $29.4-34.5$ & $27.2-31.7$ & $29.4-30.8$ & & $29.6-32.4$ \\
II & $29.4-34.5$ & $28.0-32.8$ & $28.0-33.8$ & & \\
III & $29.4-34.5$ & $29.9-31.5$ & $29.0-31.5$ & $29.0-33.6$ & $82.8-89.8$ \\
& & & & & \\
Eiweiss & $82.9-91.6$ & $80.3-88.6$ & $76.9-89.0$ & & \\
I & $82.9-91.6$ & $72.4-86.8$ & $74.2-86.0$ & & \\
II & $82.9-91.6$ & $69.1-87.7$ & $76.8-91.0$ & $79.2-89.3$ & \\
III & & & & & \\
\hline
\end{tabular}


Die freien Fettsäuren wurden durch Titrieren aus dem Fett des Eigelbs bestimmt. Wenn man die Menge der beim Titrieren verbrauchten 0.1-n $\mathrm{KOH}$ miteinander vergleicht, findet man für die frischen und für alle gelagerten Versuchsgruppen eine Variation von $0.60-0.90 \mathrm{ml}$. Während der Lagerung von vier Monaten sind keine Veränderungen aufgetreten. Die gleichen Resultate ergaben auch die Analysen über die Fette, die aus rohem und gekochtem Eigelb extrahiert worden waren. Der Gehalt der frischen, der drei Monate bei Zimmertemperatur geölt gelagerten und der vier Monate ungeölt im Kühlschrank gelagerten Eier an freien Fettsäuren ist in Tabelle 9 zu finden.

Es treten deutliche Variationen auf. Sie können darauf beruhen, dass die verschiedenen Fettsäuren eine verschiedene Fähigkeit haben, durch die Vitellinhaut in das Eiweiss zu diffundieren, sowie auf der gleichzeitig auftretenden geringen Zersetzung des Fettes im Eigelb. Ưber die Veränderungen in der Fettsäurenzusammensetzung der Eier während der Lagerung sind in der Literatur keine Angaben zu finden. Dagegen stehen die übrigen hier angeführten Resultate völlig in Übereinstimmung mit den Ergebnissen der im Ausland durchgeführten Untersuchungen.

\section{Die Veränderungen in den Proteinen}

Wie schon früher angegeben, gehen im Eiweiss von gelagerten Eiern Veränderungen vor, die schon organoleptisch festzustellen sind. Das Eiweiss wird dünnflüssig, obgleich sein Gehalt an Trockenmasse fortwährend zunimmt. Man vermutet, dass dieses Phänomen mit den Veränderungen im Ovomuzin in enge Verbindung zu bringen ist. Das Ovomuzin des Eiweisses ist seiner Struktur nach fibrös und bildet im schwach basischen Bereich eine viskose Lösung (Schulz und ANglemier 1964). Bei verstärkter basischer Reaktion wird die fibröse Struktur zerstört, und das Eiweisses wird dünnflüssig. Teilweise kann das Flüssigwerden auch von der Verbindung der Glukose mit den Proteinen des Eiweisses herrühren. Dies ist bei Eiweiss untersucht worden (FEENEY et al. 1964), aus dem die Glukose durch Dialyse entfernt worden war. In diesem Fall trat keine Dünnflüssigkeit ein; wenn jedoch Glukose wieder dem Eiweiss hinzugefügt wurde, zeigte sich sofort eine Verflüssigung des Eiweisses. Dieselbe Wirkung haben die Aldosezucker, dagegen verursachten die reduzierten Zuckerarten keine Reaktion. In ihrer im Jahre 1952 durchgeführten Untersuchung haben Evan et al. u. a. festgestellt, dass Proteine aus dem Eigelb in das Eiweiss übergehen. In ihren späteren Untersuchungen (1953 und 1958) haben sie jedoch keine entsprechenden Vorgänge feststellen können und schliessen daraus, dass die Diffusion, die bei den ersten Versuchen festzustellen gewesen ist, auf die Einwirkung des an die Hühner verfütterten Baumwollsaatöles zurückzuführen wäre. Die Menge der freien Aminosäuren im Eiweiss nimmt dagegen zu (LücK und PAvLIK 1962). Dies konnte vor allem für Glutaminsäure und Prolin festgestellt werden sowie in etwas geringerem Masse für Leucin und Serin. Methionin und Glycin nahmen sehr wenig zu, und eine noch kleinere Zunahme konnte für Cystin und Tryptophan festgestellt werden, obgleich die Eier bis zu sechs Monaten gelagert worden waren. Lück und PAVLIK (1963) geben die Mengen der freien Aminosäuren in den verschieden lange gelagerten Eiern folgendermassen an:

Gehalt an freien Aminosäuren im Eiweiss mol/g

$\begin{array}{cccc}0 \text { Monat } & 1 \text { Monat } & 2 \text { Monate } & 4 \text { Monate } \\ 0.8 & 5.8 & 6.1 & 13.5\end{array}$


DucAy et al. (1960) geben als Gehalt an freien Aminosäuren im Eiweiss 0.14 - 0.54 $\mathrm{M} / \mathrm{ml}$ und im Eigelb 38-41 M/ml an. Sie nehmen an, dass der grosse Gehalt des Eigelbs an freien Aminosäuren aus dem Blut des Huhnes stammt und die Aminosäuren im Eiweiss entsprechend entweder in der Oviductphase aus dem Eigelb übergegangen oder im Zusammenhang mit dem Entstehungsprozess der Proteine gebildet worden sind.

Die proteolytische Aktivität des Eiweisses ist im befruchteten Ei sehr gering. LINEWEAVER et al. (1949) haben festgestellt, dass ein Eiweiss, in das $12 \%$ vom Inhibitor des Trypsins eingeht, weniger als $0.004 \%$ Trypsin enthält. Beide Werte sind pro Trockenmassegehalt angegeben. Das Ovomuzin wirkt jedenfalls inhibierend auf die Tätigkeit des Trypsins und Zymotrypsins ein (Schulz und Anglemier 1964). Wegen der schwachen proteolytischen Aktivität des Eiweisses haben die Forscher (Lück und PAvLIK 1963, Ducay 1960) angenommen, dass die während der Lagerung im Eiweiss angereicherten freien Aminosäuren aus dem Eigelb hinüberdiffundiert wären. Die eventuelle Selektivität der Vitellinhaut würde die Verschiedenheit der Zunahme des Gehaltes an verschiedenen Aminosäuren erklären. LücK und PAVLIK (1963) haben weiter das Eiweiss getrennt vom Eigelb untersucht, wobei eine entsprechende Zunahme nicht festgestellt werden konnte. Im Eigelb liess sich eine kleine Zunahme der freien Aminosäuren erkennen (DucAy et al. 1960).

In der vorliegenden Untersuchung sind kleine Verminderungen in den Gesamtproteinmengen, berechnet vom Gehalt an Trockenmasse bei allen Lagerungsgruppen, feststellbar gewesen.

Tabelle 11. Die freien Aminosäuren $\mu \mathrm{g} / \mathrm{g}$ Trockenmasse des Eigelbs.

\begin{tabular}{|c|c|c|c|c|c|c|c|c|c|}
\hline \multirow[t]{2}{*}{ Aminosäure } & \multirow{2}{*}{$\begin{array}{c}\text { Frisch } \\
\text { I }\end{array}$} & \multirow[b]{2}{*}{ II } & \multicolumn{2}{|c|}{ Kühlschranck } & \multicolumn{2}{|c|}{ Zimmertemp. } & \multicolumn{3}{|c|}{ Geölt, Zimmertemp. } \\
\hline & & & 1 Mon & 4 Mon & 1 Mon & 2 Mon & 1 Mon & 2 Mon & 3 Mon \\
\hline Asparaginsãure & 150.3 & 215.3 & 236.9 & 248.4 & 251.5 & 411.0 & 162.6 & 282.8 & 220.4 \\
\hline Threonin & 413.2 & 442.2 & 418.4 & 365.9 & 383.8 & 471.1 & 377.3 & 387.0 & 412.7 \\
\hline Serin & 368.2 & 378.4 & 389.3 & 324.7 & 513.8 & 401.4 & 376.3 & 394.7 & 376.9 \\
\hline Glutaminsäure & 629.3 & 800.9 & 785.4 & 720.0 & 849.2 & 1215.2 & 666.9 & 834.2 & 669.1 \\
\hline Prolin & 267.0 & 271.6 & 333.2 & 271.6 & 348.9 & 426.7 & 299.7 & 248.8 & 331.9 \\
\hline Glycin & 108.9 & 127.7 & 128.4 & 111.9 & 138.4 & 217.4 & 130.3 & 146.5 & 147.3 \\
\hline Alanin & 162.8 & 187.6 & 182.3 & 169.4 & 221.9 & 382.4 & 187.6 & 198.1 & 211.6 \\
\hline Valin & 306.9 & 322.6 & 305.0 & 282.4 & 328.2 & 494.8 & 289.1 & 292.1 & 320.7 \\
\hline Cystein & 18.5 & 20.7 & 19.4 & 21.1 & 16.9 & 32.4 & 15.7 & 17.1 & 6.8 \\
\hline Methionin & 126.5 & 124.8 & 129.8 & 75.9 & 134.7 & 198.3 & 119.4 & 97.6 & 126.5 \\
\hline Isoleucin & 255.7 & 270.0 & 271.4 & 245.9 & 276.3 & 401.9 & 250.8 & 251.1 & 341.0 \\
\hline Leucin & 473.7 & 485.7 & 530.7 & 462.5 & 540.4 & 708.2 & 467.3 & 489.1 & 556.0 \\
\hline Tyrosin & 397.9 & 430.9 & 489.8 & 477.2 & 470.2 & 655.3 & 424.3 & 485.6 & 481.5 \\
\hline Phenylalanin & 318.7 & 296.6 & 345.6 & 325.9 & 327.4 & 468.9 & 276.9 & 297.9 & 341.5 \\
\hline$\gamma$-Aminobuttersäure & 7.8 & - & - & 14.7 & - & 11.6 & 18.2 & 3.8 & - \\
\hline Ornithin & 22.6 & 24.8 & 33.3 & 23.6 & 23.3 & 93.8 & 28.9 & 27.7 & 20.3 \\
\hline Lysin & 479.0 & 482.2 & 541.3 & 486.7 & 529.4 & 536.8 & 448.2 & 530.7 & 462.7 \\
\hline Tryptophan & 81.1 & 151.7 & 109.1 & 105.8 & 110.2 & 121.9 & 77.4 & 126.1 & - \\
\hline Histidin & 99.8 & 99.2 & 111.4 & 94.2 & 106.3 & 141.6 & 96.7 & 105.4 & 119.1 \\
\hline Arginin & 438.6 & 433.9 & 530.7 & 457.2 & 480.9 & 480.8 & 409.4 & 475.5 & 434.7 \\
\hline Insgesamt mg/g & 5.13 & 5.57 & 5.89 & 5.29 & 6.05 & 7.78 & 5.12 & 5.69 & 5.58 \\
\hline
\end{tabular}


Tabelle 12. Die freien Aminosäuren im Eiweiss $\mu \mathrm{g} / \mathrm{g}$ Trockenmasse

\begin{tabular}{|c|c|c|c|c|c|c|c|c|c|}
\hline \multirow[t]{2}{*}{ Aminosäure } & \multirow[t]{2}{*}{ Frisch } & \multicolumn{3}{|c|}{ Kühlschrank } & \multicolumn{2}{|c|}{$\begin{array}{l}\text { Zimmertem- } \\
\text { peratur }\end{array}$} & \multirow{2}{*}{$\frac{\text { Geölt }}{1 \text { Mon. }}$} & \multicolumn{2}{|c|}{$\begin{array}{c}\text { Zimmertem- } \\
\text { peratur }\end{array}$} \\
\hline & & 1 Mon. & 2 Mon. & 4 Mon. & 1 Mon. & 2 Mon. & & 1 Mon. & 3 Mon. \\
\hline Asparginsäure & 55.7 & 54.2 & 67.6 & 43.3 & 137.9 & 1031.0 & 33.7 & 122.8 & 134.4 \\
\hline Treonin & 46.1 & 69.6 & 53.7 & 54.8 & 140.1 & 971.4 & 54.3 & 98.2 & 138.2 \\
\hline Serin & 54.4 & 69.5 & 62.8 & 59.1 & 137.4 & 573.8 & 50.8 & 105.5 & 144.1 \\
\hline Glutaminsäure & 96.9 & 128.7 & 140.3 & 102.6 & 312.2 & 2705.6 & 84.0 & 246.8 & 226.1 \\
\hline Prolin & 37.9 & 58.5 & 48.8 & 46.5 & 139.6 & 1093.6 & 48.8 & 96.9 & 111.0 \\
\hline Glycin & 9.8 & 10.3 & 11.8 & 4.2 & 18.0 & 740.2 & 11.2 & 18.7 & 19.2 \\
\hline Alanin & 31.7 & 39.0 & 44.3 & 34.6 & 95.1 & 1553.3 & 32.0 & 51.7 & 76.5 \\
\hline Valin & 47.7 & 56.0 & 65.6 & 53.8 & 144.1 & 1861.0 & 60.9 & 118.3 & 132.3 \\
\hline Cystein & 4.4 & - & 4.4 & - & - & 82.4 & - & 2.9 & - \\
\hline Methionin & 17.9 & 20.5 & 20.3 & 14.2 & 51.3 & 937.3 & 28.8 & 34.6 & 38.2 \\
\hline Isoleucin & 37.7 & 42.0 & 42.6 & 39.6 & 121.0 & 1273.5 & 59.8 & 89.0 & 120.5 \\
\hline Leucin & 71.9 & 85.3 & 85.9 & 81.1 & 231.3 & 1845.1 & 132.8 & 167.4 & 201.5 \\
\hline Tyrosin & 48.3 & 64.5 & 41.8 & 61.7 & 145.9 & 1161.6 & 73.4 & 134.6 & 158.3 \\
\hline Phenylalanin & 40.6 & 43.7 & 45.9 & 41.9 & 124.0 & 1485.3 & 82.1 & 102.6 & 107.0 \\
\hline$\gamma$-Aminobuttersäure & - & - & - & - & - & 113.4 & - & - & - \\
\hline Ornithin & 4.8 & 11.4 & 7.6 & 6.3 & 53.8 & 380.2 & 6.7 & 12.3 & 13.9 \\
\hline Lysin & 6.9 & 6.7 & 6.9 & 3.5 & 14.5 & 120.6 & 24.9 & 19.5 & 2.2 \\
\hline Tryptophan & 11.7 & - & - & - & 29.6 & 393.2 & - & - & - \\
\hline Histidin & 16.2 & 18.9 & 13.8 & 11.1 & 36.5 & 249.5 & 21.4 & 30.6 & 35.1 \\
\hline Arginin & 47.3 & 62.0 & 55.7 & 56.6 & 129.2 & 59.0 & 52.1 & 94.0 & 115.5 \\
\hline Insgesamt $\mathrm{mg} / \mathrm{g}$ & 0.69 & 0.84 & 0.82 & 0.71 & 2.06 & 18.57 & 0.86 & 1.55 & 1.77 \\
\hline
\end{tabular}

Die Verminderung des Proteingehalts im Eiweiss ist in Zimmertemperatur am grössten gewesen, und zwar bei den ungeölt gelagerten Eiern der II. Gruppe. Dagegen hielt sich der Proteingehalt der ungeölt im Kühlschrank wie auch der geölt in Zimmertemperatur gelagerten Eier während der ganzen Versuchszeit auf fast dem gleichen Niveau. Im Proteingehalt des Eigelbs zeigte sich durchgehend eine kleine Abnahme, und zwischen den einzelnen Lagerungsgruppen konnten keine Unterschiede wahrgenommen werden. Die Tabellen 11 und 12 der Beilagen besagen die Gehalte an freien Aminosäuren in frischen und in gelagerten Eiern, gesondert für das Eigelb und das Eiweiss und in $\mathrm{g} / \mathrm{g}$ Trockenmasse angegeben.

Der Gesamtgehalt des Eigelbs an freien Aminosäuren zeigt verhältnismässig kleine Variationen. Während der ganzen Versuchszeit und unter allen Lagerungsbedingungen haben die Variationen 5.12-7.87 mg ausgemacht. Die deutlichste Zunahme des Gehaltes an freien Aminosäuren konnte im Eigelb der zwei Monate bei Zimmertemperatur gelagerten ungeölten Eier bei der Glutaminsäure festgestellt werden, nämlich $629-800 \mu \mathrm{g}-$ $1215 \mu \mathrm{g}$. Auch die Zunahme an Prolin, Alanin, Valin, Isoleucin, Tyrosin und Phenylalanin betrug über $100 \mu \mathrm{g}$ und ist daher als wirkliche Zunahme und nicht nur als Variation in den Gehalten der einzelnen Eier anzusehen.

Im Eiweiss ist die Situation eine ganz andere. Wenn wir die im Kühlschrank gelagerten Eier betrachten, ist die Zunahme sowohl im gesamten Gehalt an freien Aminosäuren als 
auch die der einzelnen Säuren klein gewesen und zum grössten Teil nur ein Ausdruck der normalen Variationen in den einzelnen Eiern gewesen. Ebenso verhält es sich bei den einen Monat geölt in Zimmertemperatur gelagerten Eiern. Dagegen zeigt sich nach einer Lagerungszeit von zwei und drei Monaten in einigen Gruppen eine mehr als zweifache Zunahme des Gehaltes an freien Aminosäuren.

Die grösste Zunahme erfolgte zwischen dem ersten und zweiten Lagerungsmonat: von $0,86 \mathrm{mg}$ auf $1.55 \mathrm{mg}$. Zwischen dem zweiten und dritten Monat war die Zunahme nur $0.22 \mathrm{mg}$. Am meisten stieg der Gehalt an Glutaminsäure, Leucin und Tyrosin bei dieser Gruppe. Auch der Gehalt an Asparaginsäure, Threonin, Serin, Prolin, Valin, Isoleucin und Arginin erhöhte sich bedeutend. Die zu Beginn niedrigen Gehalte an Glycin und Methionin verdoppelten sich während des zweiten und dritten Lagerungsmonats.

Die grössten Veränderungen sind jedoch bei den unbehandelten, bei Zimmertemperatur gelagerten Eiern zu verzeichnen gewesen. Schon nach einem Monat Lagerung zeigt sich eine deutliche Zunahme bei allen Aminosäuren. Nach zwei Monaten betrugen die Zunahmen in vielen Fällen schon mehr als $1 \mathrm{mg}$. Es ist interessant, dass die einzige Probe, in der $\gamma$-Aminobuttersäure nachzuweisen gewesen ist, zwei Monate bei Zimmertemperatur gelagert worden war. Auch fanden sich in dieser Gruppe reichlich Zystein und Tryptophan, das sonst nur in sehr kleinen Mengen vorzukommen pflegt: Zystin $82.4 \mu \mathrm{g}$ und Tryptophan $393.2 \mu \mathrm{g}$. Bei den anderen Proben waren die entsprechenden Werte 2.9-4.4 $\mu \mathrm{g}$ und $11.7-29.6 \mu \mathrm{g}$. Die erhaltenen Resultate weichen von den Literaturangaben ab, nach denen man nicht für alle Aminosäuren eine Erhöhung ihres Gehaltes im Eiweiss nachweisen konnte und im Eigelb überhaupt keine Erhöhung des Gehaltes an freien Aminosäuren vorkommt. Es ist jedoch zu bemerken, dass diejenigen Aminosäuren, deren Gehalt nach früheren Angaben während der Lagerung im Eiweiss zunimmt, sich auch in vorliegender Arbeit am meisten vermehrt haben. Weiter muss festgestellt werden, dass eine Lagerung von zwei Monaten bei Zimmertemperatur bedeutend schnellere Veränderungen hervorruft als die niedrigeren Lagerungstemperaturen.

\section{Die Veränderungen im A-Vitamin und Karotingehalt des Eigelbs}

BANDEMER et al. (1958) haben die Veränderungen im A-Vitamingehalt des Eies während der Lagerung untersucht und dabei festgestellt, dass der Gehalt im Jahre um ca. $10 \%$ abnimmt. Die grössten Verluste wurden nach 4-8 Monaten Lagerung festgestellt, und sie beruhen offensichtlich auf den Oxydationsvorgängen im Fett. Im Folgenden sollen die Mittelwerte der Veränderungen angeführt werden, die von den genannten Forschern gefunden worden sind. Die unteren, korrigierten Werte sind so berechnet worden, dass dabei die Veränderungen im Wassergehalt des Eigelbs während der Lagerung in Betracht gezogen worden sind.

$\begin{array}{lcccc} & \begin{array}{c}\text { Frisch } \\ \mu \mathrm{g} / \mathrm{g}\end{array} & \begin{array}{c}\text { Lagerung } \\ 13-19 \\ \text { Wochen } \\ \mu \mathrm{g} / \mathrm{g}\end{array} & \begin{array}{c}\text { Lagerung } \\ 28-32 \\ \text { Wochen } \\ \mu \mathrm{g} / \mathrm{g}\end{array} & \begin{array}{c}\text { Lagerung } \\ 52-54 \\ \text { Wochen } \\ \mu \mathrm{g} / \mathrm{g}\end{array} \\ & & & & \\ \text { Unkorrigierter Wert } & 3.52 & 3.14 & 2.59 & 2.73 \\ \text { Korrigierter Wert } & 3.52 & 3.57 & 2.69 & 2.81\end{array}$


Tabelle 13. Die mittleren Gehalte an A-Vitamin und Karotin pro g Trockenmasse.

\begin{tabular}{|c|c|c|c|c|c|}
\hline & \multirow{2}{*}{$\begin{array}{l}\text { Frisches } \\
\text { Eiweiss }\end{array}$} & 2 Monate & \multirow{2}{*}{$\begin{array}{c}\text { Lagerung } \\
\text { II }\end{array}$} & \multirow{2}{*}{$\begin{array}{c}4 \text { Monate } \\
\text { III }\end{array}$} & \multirow{2}{*}{$\frac{\text { Lagerung }}{\text { IV }}$} \\
\hline & & I & & & \\
\hline A-Vitamin IE & 27.5 & 24.4 & 26.0 & 24.7 & 26.4 \\
\hline $\begin{array}{l}\text { A-Vitamin } \mu \mathrm{g} / \mathrm{g} \text { Gewicht } \\
\text { (Wassergehalt beachtet) }\end{array}$ & 4.3 & 3.8 & 3.9 & 3.8 & 4.1 \\
\hline $\begin{array}{l}\text { Karotenoide } \mu \mathrm{g} \\
\text { (als } \beta \text {-Karotin berechnet) }\end{array}$ & 5.0 & 3.6 & 3.1 & 3.1 & 3.8 \\
\hline
\end{tabular}

In Tabelle 13 sind die in vorliegender Arbeit erhaltenen Resultate in IE/g Trockenmasse und nicht pro Gesamtgewicht, wie in der referierten Untersuchung angegeben. Zum Vergleich sind in der Tabelle auch die A-Vitamingehalte, in $\mu \mathrm{g}$ vom Gesamtgewicht berechnet, angeführt.

Die Abnahme im mittleren Gehalt an A-Vitamin ist noch nach einer Lagerung von vier Monaten im Kühlschrank recht gering gewesen. Diese Feststellung stimmt völlig mit den Angaben in der Literatur überein. In vorliegender Untersuchung wurden beim AVitamingehalt im Gegensatz zu den übrigen Resultaten für die verschiedenen Betriebe grosse Unterschiede festgestellt. Für die frischen Eier beliefen sich die Variationen in den A-Vitamingehalten auf 23.8-30.8 IE pro g Trockenmasse. Bei den vier Monate gelagerten Eiern betrugen die Variationen 19.3-35.9 IE, wobei die Eier des Betriebes, die im frischen Zustand den grössten Wert $30.8 \mathrm{IE}$, ergaben, nach der Lagerung den niedrigsten Wert, 19.3 IE, aufwiesen. Offensichtlich kommen allgemein im A-Vitamingehalt der Eier grosse Variationen vor, die in künftigen Untersuchungen weiter verfolgt werden sollen. Auch in bezug auf die Karotinoide treten verhältnismässig grosse Unterschiede zwischen den Betrieben hervor. Nach den Mittelwerten zu urteilen, kann während der Lagerung eine kleine Senkung des Gehaltes an Karotinoiden vorkommen.

\section{Zus a m menfassung}

In vorliegender Arbeit wurden die Veränderungen in Eiern untersucht, die in Zimmertemperatur, geölt in Zimmertemperatur sowie im Kühlschrank $\left(6^{\circ} \mathrm{C}\right)$ gelagert worden waren. In den Tabellen sind die Gewichtsverluste, die Veränderungen im Trockenmassegehalt, den Gehalten an Gesamtfett und Protein sowie im Gehalt an freien Aminosäuren, sowohl im Eigelb als auch im Eiweiss, angegeben .Auch sind die Veränderungen in der Jodzahl des Fettes, die Zusammensetzung der Triglyzeride und der Gehalt an freien Fettsäuren sowie die Veränderungen der A-Vitamin- und Karotingehalte des Eigelbs in Tabellen angegeben.

Die Resultate sind mit den Angaben der Literatur verglichen worden. Die Unterschiede sind in den freien Aminosäuren am grössten. In der Literatur findet man keine Angaben über eine Erhöhung der freien Aminosäuren des Eigelbs während der Lagerung. Nach einer Lagerung von zwei Monaten bei Zimmertemperatur konnte jedoch in vorliegender Untersuchung im Eigelb eine deutliche Erhöhung des Gehaltes an freien Amino- 
säuren festgestellt werden, von 5.13-5.57 mg in den frischen Eiern auf $7.78 \mathrm{mg}$ in den gelagerten Eiern. Die grösste Zunahme wurde für die Glutaminsäure gefunden, nämlich von $629-800 \mu \mathrm{g}$ auf $1215 \mu \mathrm{g}$. Eine Zunahme von mehr als $100 \mu \mathrm{g}$ liess sich weiter für Prolin, Alanin, Valin, Isoleucin, Leucin, Tyrosin und Phenylalanin erkennen.

In der Literatur finden sich Angaben über die Zunahme des Gehaltes an gewissen Aminosäuren. In vorliegender Arbeit wurde eine Zunahme des Gehaltes an allen Aminosäuren während der Lagerung festgestellt, die Zunahme war am höchsten bei den Aminosäuren, über die auch in der Literatur gesagt wird, dass ihr Gehalt steigt.

Nach den Angaben der Literatur beginnt sich nach einer Lagerungszeit von vier Monaten in den A-Vitamingehalten eine Abnahme zu zeigen. Die ersten Beobachtungen hierüber wurden in vorliegender Untersuchung gerade nach einer Lagerungszeit von vier Monaten gemacht. Nach diesen variierten die Gehalte an A-Vitamin von 19.3-35.9 IE pro Trockenmasse. In den frischen Eiern betrugen die Variationen 23.8-30.8 IE.

\section{LITERATUR}

A.O.A.C. Official methods of analysis 10th ed. Washington DC, 1965.

Bandemer, S. L., Evans, R. J., and Davidson, J. A., 1958. The vitamin A content of fresh and stored shell eggs. Poult Sci. 37: 538-543.

Bigbee, D. G., Dawson, L. E., Davidson, J. A., Mallman, W. L., and Houghtby, G. A., 1962. Evaluation of an oil-in-water emulsion for cleaning eggs. Poult. Science 41: 1947-1953.

Ducay, E. D., Kline, L., and Mandeles, S., 1960. Free amino acid content of infertile chicken eggs. Poult. Sci. 39: $831-835$.

Evans, R. J., Davidson, J. A., Bauer, D., and Butrs, H. A. 1952. Transfer of protein from white to yolk during the storage of shell eggs produced by hens fed cottonseed oil. Ibid. 31: 915.

Evans, R. J., Davidson, J. A., and BAuER, D. 1953. Losses of certain aminoacids during storage of shell eggs. Ibid. 32: 898.

Evans, R. J., Davidson, J. A., Bauer, D. H., and Bandemer, S. L. 1958. Distribution of proteins in fresh and stored shell eggs. Ibid. $37: 81-89$.

Evans, R. J., Bandemer, S. L., and Davidson, J. A. 1967. Lipids and fatty acids in eggs. Ibid. 46: 151-155.

Feeney, R. E., Carlary, J. J., and Clark, J. R. 1964. A reaction between glucose and egg white proteins in incubated eggs. Nature 201: 192-193.

Froning, G. W., and Swanson, M. H. 1962. Oiled versus unoiled eggs for short storage periods. 1 The effect of time and method of oiling. Poult. Sci. 41: 1880-1886.

Grzimek, B., 1964. Das Eierbuch. Siebente Auflage. Fritz Pfenningstorff Berlin-Lichtefelde (West) und Stuttgart.

Kaufman, H. P. 1958. Analyse der Fette und Fettprodukte, 1. Springer Verlag. Berlin-GöttingenHeidelberg.

Knowles, N. R. 1962. The preservation of eggs. Hawthorn, J. and Leitch, J. M.,' Recent advances in food Science p. 224-233. Butterworths London.

Lineweaver, J., Fraekel-Conrat, H., and Bean, R. S. 1949. Determination of trypsin in the presence off egg white trypsin inhibitor and demonstration of absence of trypsin from egg white. J. Biol. Chemistry 177: 205-207.

LısıтzıN, P. 1960. Kananmunien varastointi, säilytys ja jalostus. S. eläinlääkärilehti 66 : $315-317,385$ 394.

Lück," H. und PAvLrk, A. 1963. Veränderungen der freien Aminosäuren in Schaleneiern während der Lagerung. Z. Lebensm. Unters. und Forsch. 123: 282-293.

Paulenz, J. und Engst, R. 1964. Zum Ammoniakgehalt von Eiklar und Eigelb. 2 Mitt. Über den Einfluss der Lagerung auf Ammoniakgehalt und Frischezustand von Schaleneiern. Nahrung 8: 567-576.

Romanopr, A. L., and Romanory, A. J. 1963. The avian egg. John Wiley \& Sons. Inc., New York. 
Sмrт, C. F. 1959. Shell egg deterioration: Diffusion of yolk lipids into albumen as the natural cause of failures in performance. Poult. Sci. 38: 181-192.

Wetser, H. H. 1962. Practical food microbiology and technology. The Avi Publishing Co. Inc. Westport, Connecticut.

Schwall, D. V., Gardner, F. A., and Parnell, E. D. 1961. Effects of treating on shell egg quality during short term refrigerated storage. Poult. Sci. 40: 583-588.

Schultz, H. W. and Anglemier, A. F. 1964. Symposium of foods: Proteins and their reaction. The Avi Publishing Company, Inc. Westport, Connecticut.

Winton, A. L., and Winton, K. B. 1949. The structure and composition of foods. Vol III. John Wiley \& Sons Inc. New York.

\title{
SELOSTUS
}

\section{KANANMUNIEN KESTÄVYYTTÄ KOSKEVIA TUTKIMUKSI}

\author{
Merimaja Kyti ja Lauri Tuomainen \\ Maitotaloustuotteiden tarkastuslaitos, Helsinki \\ Helsingin yliopiston maitotalouslaitos
}

Säilyvyyttä koskevissa tutkimuksissa kananmunat jaettiin kolmeen ryhmään, joista ryhmä I säilytettiin jääkaapissa, ryhmä II huoneenlämpötilassa ja ryhmä III öljyttynä huoneenlämpötilassa (Clearolvalkoöljy).

Painohäviöprosenttien mediaanit olivat kahden säilytyskuukauden jälkeen ryhmässä I $6.6-9.2 \%$, ryhmässä II 16.3-18.8 \% ja ryhmässä III 1.9-9.1 \%. Huoneenlämpötilassa tapahtuva voimakas haihtuminen ilmenee painohäviön lisäksi valkuaisen kuiva-ainepitoisuuden runsaassa nousussa. Ryhmässä II on valkuaisen kuiva-ainepitoisuus ollut kahden säilytyskuukauden jälkeen 17.6-19.0 \%, ryhmässä III $13.1-16.4 \%$ (tuoreissa munissa se vaihtelee $11.2-14.8 \%$ ). Öljytyissä kananmunissa ovat keskinäiset vaihtelut olleet suuria, johtuen siitä, ettei öljyämiselle sopivinta ajankohtaa, 8-12 tuntia muninnasta, voitu noudattaa kaikista kanaloista saatujen kananmunien kohdalla kuljetusvaikeuksien vuoksi.

Säilytyksen aikana keltuaisen kuiva-ainepitoisuus pienenee valkuaisesta keltuaiseen suuntautuvan veden diffundoitumisen vaikutuksesta. Vähiten diffuusiota on tapahtunut jääkaapissa säilytetyissä kananmunissa.

Rasvan kokonaismääriä tutkittaessa on kahden kuukauden ja sitä pitemmän säilytysajan jälkeen todettu valkuaisessa lievää rasvapitoisuuden kohoamista. Tämä rasva on ilmeisesti siirtynyt diffundoitumalla keltuaisesta. Keltuaisen rasvapitoisuudessa on puolestaan tapahtunut pientä vähentymistä. Esimerkiksi neljä kuukautta jääkaapissa säilytetyissä kananmunissa oli valkuaisen kuiva-aineen rasvapitoisuus $0.5-0.7 \%$ (tuoreissa $0.2-0.5 \%$ ). Kananmunien kokonaisrasvaa ja sen fraktioita tutkittaessa ei havaittu mitään merkittäviä eroavuuksia tuoreiden ja eri tavoin säilytettyjen kananmunien välillä. Vapaiden rasvahappojen määrissä ei myöskään saatu esille eroja. Sensijaan niiden rasvahappokoostumuksessa oli jonkin verran vaihtelua, johon on saattanut vaikuttaa toisaalta eri rasvahappojen erilainen kyky diffundoitua vitelliinikalvon läpi, toisaalta keltuaisen rasvan vähäinen hajoaminen. A-vitamiini- ja karotiinipitoisuuksissa vaihtelut ovat suhteellisen suuria eri kananmunien kesken. Mitään varsinaista vitamiinipitoisuuden pienenemistä ei säilytyksen aikana havaittu. Kirjallisuuden mukaan alkaa A-vitamiinin väheneminen vasta neljän säilytyskuukauden kuluttua ja näissä tutkimuksissa viimeinen määritys suoritettiin juuri neljän kuukauden săilytysajan jälkeen.

Proteiinien kokonaispitoisuudessa on keltuaisessa ollut pientä laskua kaikissa säilytysryhmissä, valkuaisessa vain huoneenlämmössä öljyämättä säilytetyissä munissa. Vapaiden aminohappojen lisääntymistä ei kirjallisuuden mukaan ole havaittu keltuaisessa. Näissä tutkimuksissa on kuitenkin huoneenlämmössä säilytetyissä kananmunissa keltuaisen vapaiden aminohappojen määrä kohonnut yhden säilytyskuukauden aikana 5.13-5.57 mg:sta/g $6.05 \mathrm{mg}: a a n / g$ ja kahden kuukauden kuluttua $7.78 \mathrm{mg}$ :aan/g. Selvintå on 
lisääntyminen ollut glutamiinihapon kohdalla: $629-800 \mu \mathrm{g}$ :sta $1215 \mu \mathrm{g}$ :aan/g. Jääkaapissa säilytetyissä kananmunissa valkuaisen vapaiden aminohappojen määrät ovat pysyneet tuoreista saatujen lukemien tasolla. Sen sijaan öljyttynä huoneenlämmössä olleissa munissa esiintyy jo selvää vapaiden aminohappojen lisääntymistä ja huoneenlämmössä käsittelemättöminä säilytetyissä lisäykset ovat huomattavia. Esimerkiksi tuoreen munan lukemaa $0.69 \mathrm{mg} / \mathrm{g}$ vastaa yhden kuukauden kuluttua lukema $2.06 \mathrm{mg} / \mathrm{g}$ ja kahden kuukauden kuluttua $18.57 \mathrm{mg} / \mathrm{g}$. Kaikkien aminohappojen kohdalla on tässä ryhmässä havaittavissa selvää lisääntymistä jo yhden säilytyskuukauden kuluttua.

Saadut tulokset poikkeavat jonkin verran kirjallisuudessa esitetyistä tiedoista, joiden mukaan kaikissa aminohapoissa ei lisääntymistä ole todettu. Kuitenkin ne aminohapot, joiden määrien on valkuaisessa todettu lisääntyneen, ovat tämänkin tutkimuksen mukaan lisääntyneet eniten. Lisäksi on otettava huomioon, että kaksi kuukautta huoneenlämpötilassa säilytettynä pitäminen aiheuttaa huomattavasti nopeampia muutoksia kuin alhaisemmat säilytyslämpötilat. 